\title{
Saúde Masculina: representação e experiência de homens trabalhadores com o corpo, saúde e doença.
}

Marco AntonioAlves Separavich ${ }^{1}$

Orientador: Profa. Dra. Ana Maria Canesqui

Tese (Doutorado), 2014.

Data de defesa: 14.08 .14

Texto integral disponível em: $\underline{\text { http://www.bibliotecadigital.unicamp.br/ }}$ document $/$ code $=000941003 \&$ opt $=4$

Este estudo analisou as experiências e representações de homens trabalhadores com o corpo, saúde, doença e cuidado, e os problemas principais de saúde por eles percebidos, quais sejam, a hipertensão arterial e as lombalgias crônicas. Analisou-se como explicam as suas causas; a forma como enfrentam e buscam a resolução ou mitigação desses problemas de saúde, as terapêuticas utilizadas, a interferência que elas acarretam em suas rotinas de vida e identidades. A revisão da literatura da Saúde Coletiva sobre a saúde do homem e masculinidades mostrou que as demandas masculinas na busca por tratamentos nos serviços públicos de saúde e a percepção de que são portadores de necessidades específicas de saúde são minoritárias. Constatou-se também que as abordagens socioantropológicas de como eles convivem e lidam com as enfermidades que os acometem também são raras. Justifica-se, portanto, o interesse e as razões que motivaram este trabalho. As demandas minoritárias masculinas aos serviços de saúde, concebidas a partir da masculinidade tradicional socialmente vigente, e os dados epidemiológicos das altas taxas de morbimortalidade masculina, embasaram a formulação da Política Nacional de Atenção Integral à Saúde do Homem (PNAISH), cujos objetivos buscam promover a melhora da saúde da população masculina na faixa etária dos 20 aos 59, facilitando o seu acesso aos serviços de atendimento integral à saúde na atenção primária. Campinas abriga projeto piloto de tal política. Analisou-se o processo de implementação da PNAISH em um dos centros de saúde da cidade elegido como piloto, cujos serviços estruturam-se na Estratégia Saúde da Família. Entrevistou-se 9 profissionais que nele atuam, especificamente na saúde do adulto, considerando o conhecimento que têm de tal política, as atividades que realizam para o seu atendimento, e os obstáculos observados que dificultam a sua implementação. Para o estudo da experiência da enfermidade com a hipertensão e dores lombares crônicas, entrevistou-se 15 homens, com média etária 56 anos, residentes no bairro da unidade de saúde em questão e que utilizaram em algum momento o serviço público de saúde. As entrevistas de todos os entrevistados foram transcritas, lidas exaustivamente para identificar os temas recorrentes. Na análise, os temas classificados foram distribuídos em categorias gerais, como corpo masculino, 1 Programa de Pós-Graduação em Saúde Coletiva, Faculdade de Ciências Médicas, Universidade Estadual de Campinas, SP.mseparavich@hotmail.com 


\section{$254 / /$}

cuidados, problemas de saúde, interpretando-os à luz das leituras socioantropológicas realizadas e sempre que possível, articulando a experiência e as representações da enfermidade, através dos relatos interpretados pelo pesquisador. Concluiu-se que as experiências da enfermidade são sempre peculiares e biográficas, no entanto, trazem consigo referências sociais e culturais mais amplas, devendo ser ambas consideradas, para não cobrir de opacidade, tanto as experiências quanto as representações, as pessoas que as vivem e os modos de interpretá-las e significá-las. O estudo da experiência da enfermidade pode, assim, contribuir para a reflexão sobre a inserção e visibilidade masculinas nos serviços públicos de saúde, ampliando o olhar dos agentes implementadores da política de saúde do homem sobre suas ações.

Palavras-chave: Ciências sociais em saúde; Saúde do homem; Corpo humano; Gênero e saúde; Políticas públicas de saúde. 